\title{
Predictive Control in Matrix Converters - Part II: Control Strategies, Weaknesses and Trends
}

\author{
M. Rivera, Member, IEEE, P. Wheeler, Fellow Member, IEEE, and A. Olloqui, Student Member, IEEE,
}

\begin{abstract}
The second part of this paper presents an overview of different control strategies and applications for matrix converters (MCs) where predictive control techniques are applied. It will be shown that predictive control is a promising alternative to control MCs due to its simplicity and flexibility to include different constrains in the control for different industrial applications such as renewable energies, grid interconnection, multi-drives systems control, among others. In addition, some limitations and weaknesses of predictive control in MCs will be discussed as well as some future trends and applications.
\end{abstract}

Index Terms-Matrix Converter, Direct Matrix Converter, Indirect Matrix Converter, Power Control, Predictive Control, Control Strategies, Sinusoidal Current, Voltage control, AC-AC conversion, Modulation Schemes

\section{INTRODUCTION}

Model predictive control (MPC) offers a flexible and better alternative for the control of electrical energy with power electronics converters. This new approach takes into consideration the discrete and nonlinear nature of power converters and drives and promises to have a strong impact on control in power electronics in the near future.

In the second part of this paper, a review of several predictive control schemes proposed for different topologies of MCs and their applications will be presented. It will be demonstrated that these techniques can be easily implemented by taking advantage of the available technologies of digital signal processors. Also limitations and/or weaknesses in a comparison to conventional control concepts as well as open questions and future trends are discussed in the final part of this paper.

\section{Predictive Control Strategies and APPLICATIONS FOR MATRIX CONVERTERS}

Based on the review done by the authors, there are several implementations of predictive control applied to MCs. As indicated in Fig. 1, the most relevant techniques correspond to predictive current control (PCC) and predictive torque control (PTC). It is possible also to find some implementations of predictive reactive/active power control (PPC), and predictive voltage control (PVC) where an $L C$ filter is considered in the output side of the converter [1].

\section{A. Predictive Current Control}

In the group of PCC, different have been the implementations which are focused to specific applications and objectives. The basic PCC strategy has been presented in the first part of this paper, where only the load current is controlled [2]. In this case, the cost function includes only the error between the load current references and their respective predictions but the source currents are highly distorted, which is an undesired performance for the MC. For this reason, in order to improve the input current behavior, a new term is included in the cost function, where an instantaneous reactive input power minimization is considered, as reported in [3]-[17].

The control scheme with this implementation is detailed in Fig. 2, where the cost function is now defined as:

$$
g(k+1)=\triangle i_{o}+\gamma_{q} \triangle Q
$$

with $\triangle i_{o}=\left|i_{a}^{*}-i_{a}^{p}\right|+\left|i_{b}^{*}-i_{b}^{p}\right|+\left|i_{c}^{*}-i_{c}^{p}\right|$, and $\triangle Q=$ $\left|Q^{*}-\left(v_{s \alpha} i_{s \beta}-v_{s \beta} i_{s \alpha}\right)\right|$. By including this new term, a significant improvement of the input current performance is obtained while maintaining the good behavior of the load current. An important issue here is the weighting factor selection. There are some guidelines to determine this value which can be reviewed in [18]. As observed, by including the instantaneous reactive power minimization on the input side, is possible to obtain unity power factor. However, one interesting issue that have been observed is that the PCC with reactive power minimization method is very sensitive to the distortion of the source voltage and the resonance of the input filter and thus, this affects the output waveform distortion level, particularly when harmonic distortion is existing in the source voltage. In addition, one drawback in the operation of a $\mathrm{MC}$ with predictive control is the variable switching frequency. Because at every sampling time is selected a switching state to be applied to the converter, is possible to have the same optimal state for a while, which will produce a variable switching frequency and thus, a spread spectrum. This variable switching frequency, along with disturbances in the source voltage, could produce a resonance in the input filter generating high distortion on the input current which are also reflected in the output current due to the direct connection between input and output sides of the converter. In order to solve this problem, in [19]-[22], an input filter resonance mitigation have been proposed, based on the control scheme presented in Fig. 3.

Active damping is a control approach used for achieving an attenuation of the resonance, which avoid the disadvantages of using passive damping which has a negative impact on system efficiency. The main idea of this implementation is to emulate a virtual resistor, which is immune to system parameter variations, in parallel to 


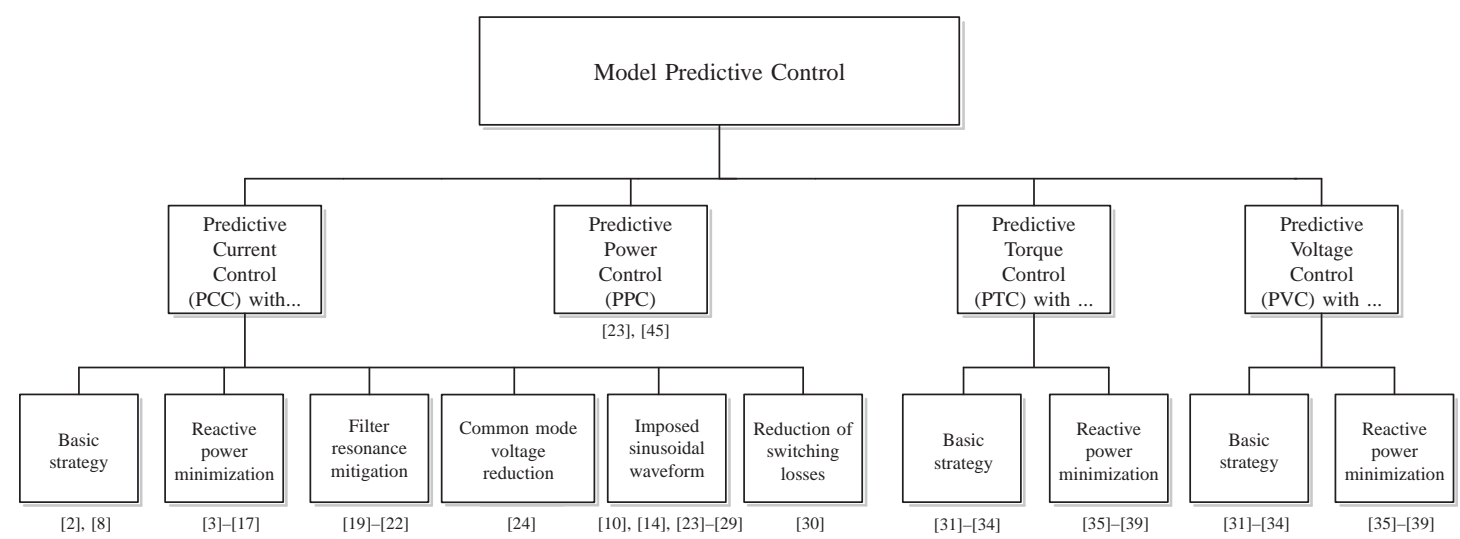

Fig. 1. Predictive control strategies applied to MCs.

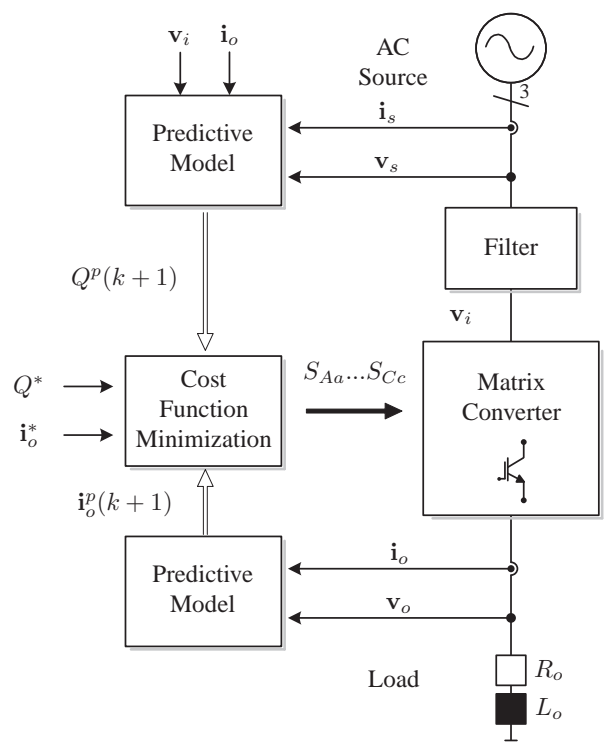

Fig. 2. Block diagram of the predictive current control strategy with instantaneous reactive input power minimization.

the capacitor of the input filter for reducing the harmonics level without affecting the first harmonic component. The power converter draws a damping current that is proportional to the capacitor voltage. Then, the active damping approach in the matrix converter is achieved by passing the harmonic component effects existing in the input side to the output side of the converter, adding this effect on the reference value of the output current. For this case, is used the same cost function defined in eq. (1), and the only difference is given by the way that the output current reference is obtained. As reported in [19]-[22], the performance of the system is improved, mitigating the resonance of the input filter and obtaining a more sinusoidal source current. This strategy reduces also the power losses comparing to the method with resistive damping. The cost of such improvement is an inclusion of additional virtual resistor in the predictive control algorithm.

Another alternative, that minimizes the instantaneous reactive power without the use of active damping, is to

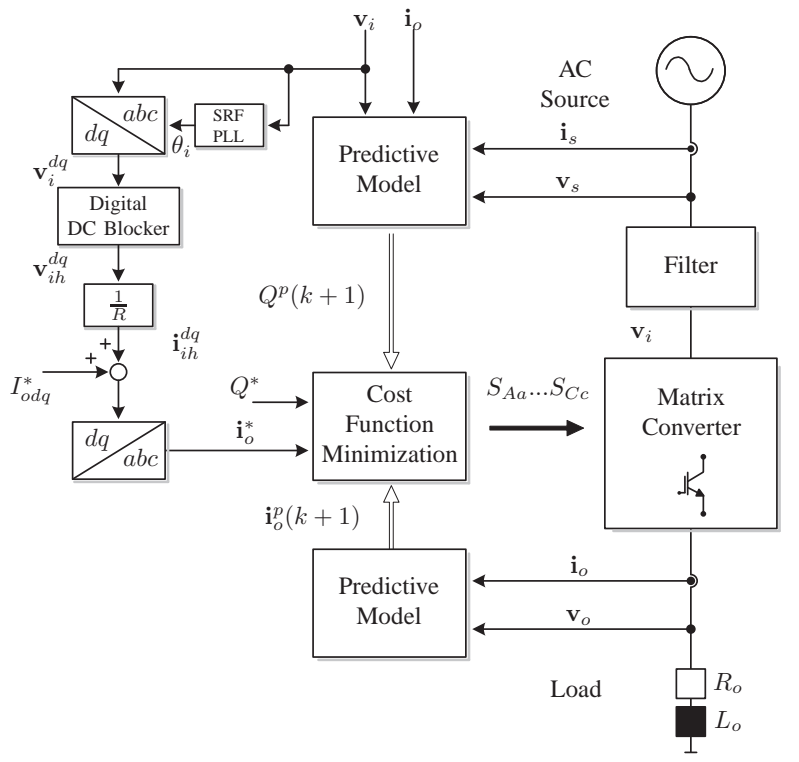

Fig. 3. Block diagram of the predictive current control strategy with active damping implementation.

force the source current to follow a sinusoidal reference value, regardless the distortion level at the input side. The block diagram of this new control method is presented in Fig. 4 and the cost function is defined as:

$$
g(k+1)=\triangle i_{o}+\gamma_{i} \triangle i_{s}
$$

where $\triangle i_{s}=\left|i_{s A}^{*}-i_{s A}^{p}\right|+\left|i_{s B}^{*}-i_{s B}^{p}\right|+\left|i_{s C}^{*}-i_{s C}^{p}\right|$.

The results shown in [10], [14], [23]-[29] demonstrated that by imposing a given waveform for the source current, it is possible to obtain a better performance than an instantaneous reactive power minimization, reducing the total harmonic distortion (THD) of both input and load currents, reducing the resonance of the input filter and consequently, extending the capacitors life-span. The source current reference and its amplitude are obtained such as reported in [10], [14], [23]-[29], and they are defined by:

$$
I_{s}=\frac{-\lambda V_{s} \pm \sqrt{\left(\lambda V_{s}\right)^{2}-4 \lambda R_{f} R_{o} I_{o}^{* 2} / \eta}}{-2 \lambda R_{f}}
$$




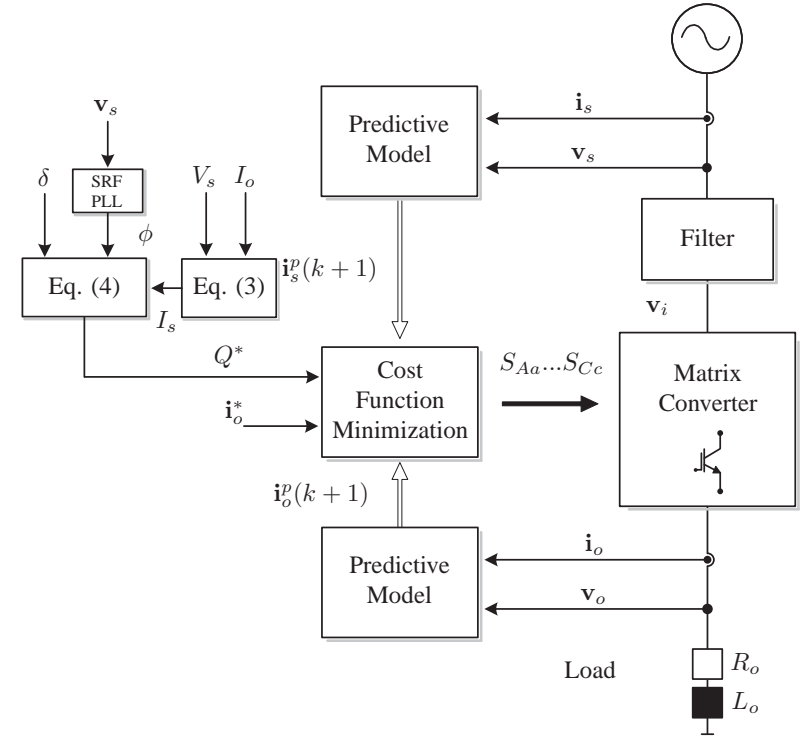

Fig. 4. Block diagram of the predictive current control strategy with imposed sinusoidal input waveform.

where $\lambda=1-8 \pi^{2} f_{s}^{2} C_{f} L_{f}$.

$$
\begin{aligned}
& i_{s A}^{*}=I_{s} \sin \left(w_{s} t+\theta\right) \\
& i_{s B}^{*}=I_{s} \sin \left(w_{s} t-2 \pi / 3+\theta\right) \\
& i_{s C}^{*}=I_{s} \sin \left(w_{s} t+2 \pi / 3+\theta\right)
\end{aligned}
$$

In [15] is presented an interesting contribution where a different approach is done to control an induction machine with PCC with instantaneous reactive power minimization. The block diagram of this implementation is shown in Fig. 5. There is possible to differentiate a predictive stage that performs PCC and a classic stage that controls the speed, flux, and torque control using field oriented control (FOC), which provides the reference currents for the predictive control stage. The cost function is defined as such as eq. (1). With this strategy, predictive control has been demonstrated as a very powerful tool opening new possibilities in the control of power converters in a very simple way.

Similarly, a PCC for an induction machine with an increment of the efficiency and a reduction of switching losses of the converter is proposed in [30]. The control scheme is the same as the diagram shown in Fig. 5, because only the cost function is modified. In order to reduce the switching frequency and thus increment the efficiency of the converter, the idea of the method consists in to include in the cost function the number of commutations needed to transit from the actual switching state being evaluated.

This is represented as:

$$
g(k+1)=\triangle i_{o}+\gamma_{q} \triangle q+\gamma_{s w} n
$$

where $n$ is the number of switches commutations considered by choosing the evaluated state. This new term in the cost function means that changing the state of the converter will have a cost. Therefore, the controller will select as optimal, the switching state that involves and

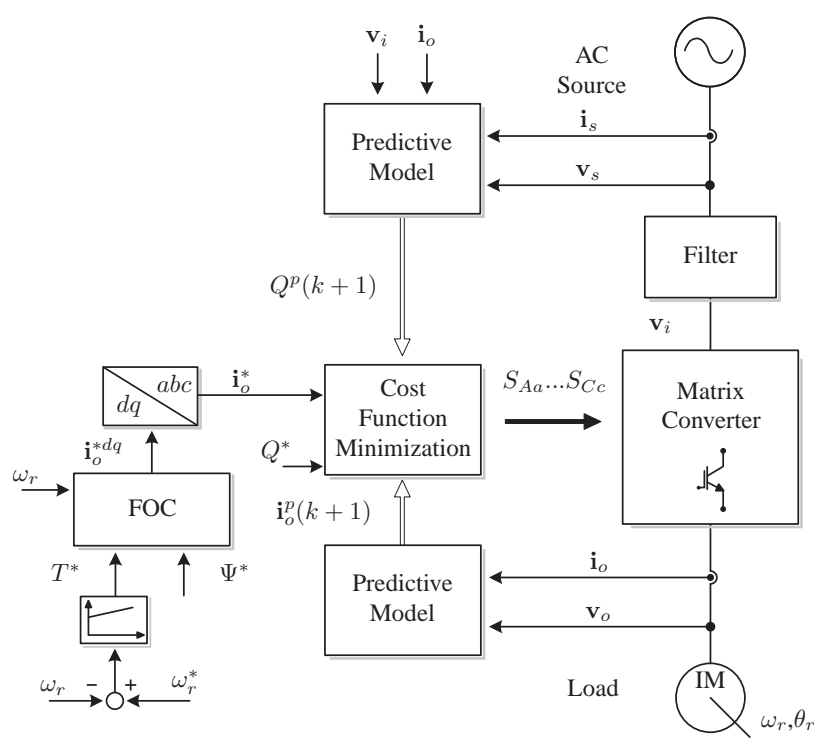

Fig. 5. Block diagram of the predictive current control strategy for torque and flux control with minimization of the input reactive power.

produces less commutations.

With the goal to reduce the switching losses of the converter, a variation for the PCC method was proposed also in [30]. The idea of this technique is to predict not only the number of commutations, but also the switching losses that the switching of the power converter would produce, and then, include that prediction in the cost function, which is defined as:

$$
g(k+1)=\triangle i_{o}+\gamma_{q} \triangle q+\gamma_{s l} \sum_{i=1}^{18} \triangle i_{c}^{(i)} \triangle v_{c e}^{(i)}
$$

where $\triangle i_{c}^{(i)}$ and $\triangle v_{c e}^{(i)}$ are variations of the collector current and collector-emitter voltage of the power transistor $i$, respectively. Note that 18 correspond to the eighteen switches of a DMC. As reported in [30], by considering these terms in the cost function, an important increment in the efficiency of the converter is obtained.

As previously demonstrated, one advantage of model predictive control is the possibility to include several control objectives in the cost function, which could be the current, voltage, reactive power, switching frequency, switching losses, torque, flux, etc. By considering this approach, in [24], a PCC with imposed source current is proposed and this strategy is enhanced with a commonmode voltage (CMV) reduction. The control strategy for this implementation is shown in Fig. 6 and the considered cost function is given by:

$$
g(k+1)=\triangle i_{o}+\gamma_{i} \triangle i_{s}+\gamma_{v}\left|v_{c m}(k+1)\right|
$$

where the common-mode voltage is defined as $v_{c m}=$ $\left(v_{a}+v_{b}+v_{c}\right) / 3$. The results showed in [24], demonstrate that just by including a new term in the cost function is possible to have simultaneous control of the input and output (source and load) currents with waveforms according their references and with reduction of the common-mode voltage. 


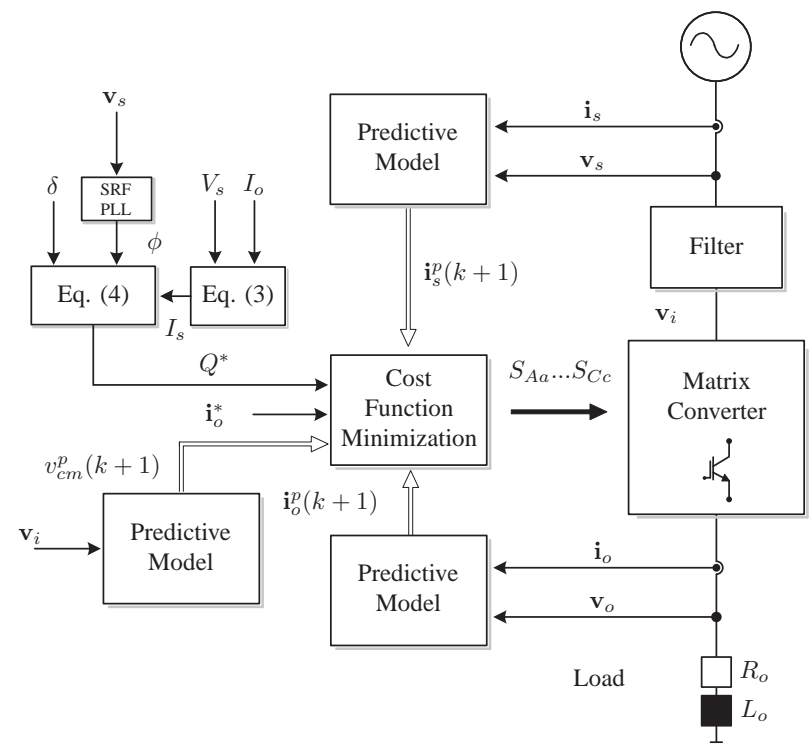

Fig. 6. Block diagram of the predictive current control strategy with common-mode voltage minimization and imposed sinusoidal input waveform.

\section{B. Predictive Torque Control}

In Fig. 7 is shown the control scheme for the basic predictive torque strategy. This control method has been introduced in [31]-[34]. Similar to the PCC method, predictive torque control (PTC) consists of selecting, at fixed sampling periods, one of the possible switching states of the matrix converter. Again, the selection of the switching state for the next time instant is performed by using a predefined cost function with proper minimization technique. This cost function $g$ represents the evaluation criteria in order to select the best switching state for the next sampling interval. For the computation of the cost function $g$, the input current $\mathbf{i}_{\mathbf{s}}$, the electromagnetic torque $T_{e}$, and the stator flux $\psi_{\mathbf{s}}$ are predicted in the future sampling period, using the mathematical model of the input filter and the induction machine (IM). A PI controller is adopted to generate the reference torque $T_{e}^{*}$ for the predictive control algorithm.

A mathematical discrete-time model is elaborated to predict the behavior of the system under a particular switching state, based on dynamic model for the IM [31]-[34]. This model is used in our case to predict the stator flux and the electromagnetic torque produced by the machine during the next sampling period. In this case, the cost function is composed of the absolute errors of the predicted torque, flux magnitude and reactive input power, resulting in:

$$
g=\triangle T_{e}(k+1)+\gamma_{\psi} \triangle \psi(k+1)
$$

where $\gamma_{q}$ and $\gamma_{\psi}$ are weight factors selected to define the relation between reactive input power, torque and stator flux conditions. In Fig. 8 is presented the same strategy but enhanced with instantaneous reactive power minimization in order to improve the performance of the converter in the input side. For this case, the cost function

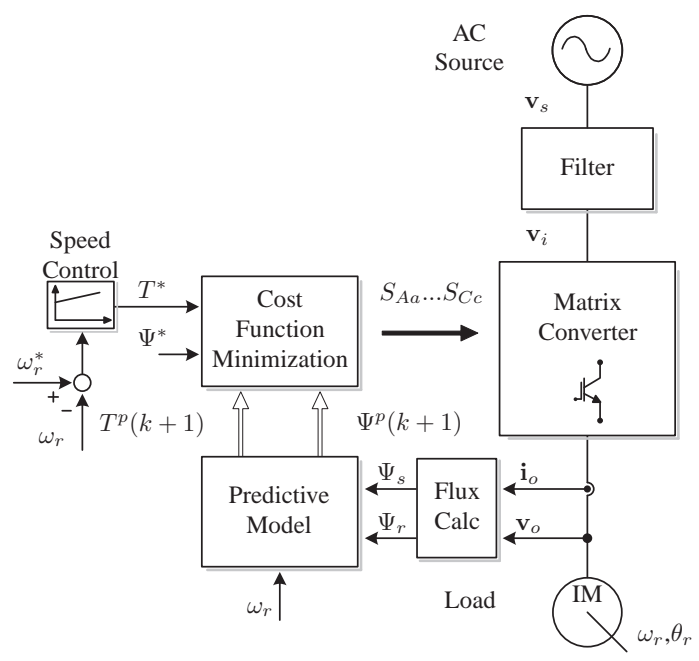

Fig. 7. Block diagram of the predictive torque and flux control strategy.

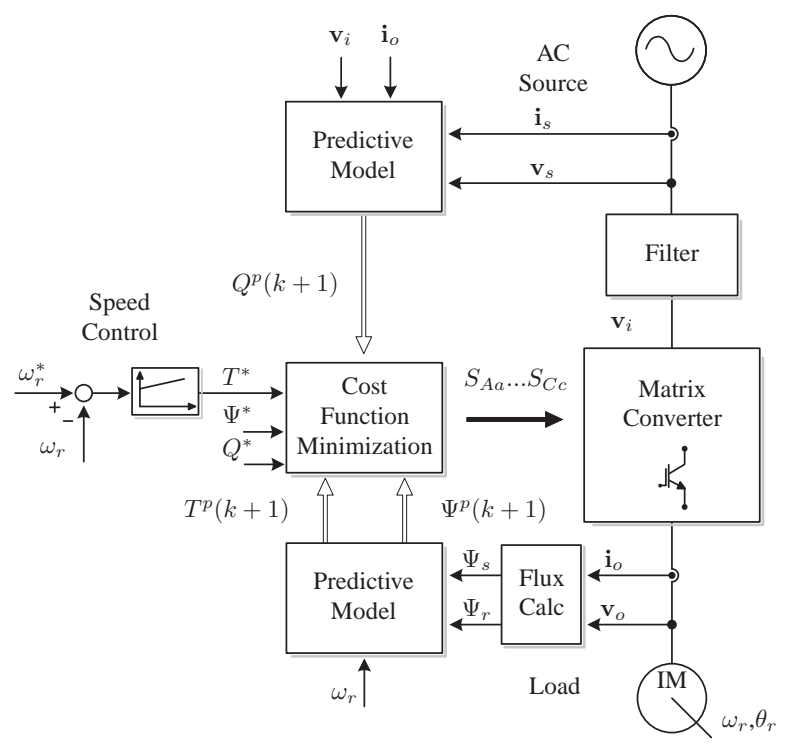

Fig. 8. Block diagram of the predictive torque and flux control strategy with minimization of the instantaneous input reactive power.

is given as

$$
g=\triangle T_{e}(k+1)+\gamma_{\psi} \triangle \psi(k+1)+\gamma_{q} \triangle q_{s}(k+1)
$$

As reported in [35]-[39], the method is very simple and effective with a very fast dynamic response of the electrical torque and a decoupled control respect to the stator flux control maintaining, at the same time, unity displacement power factor for both motoring and regeneration operation modes. All these remarkable characteristics make PTC a suitable alternative to the well known direct torque control (DTC) having the advantages of be simpler and consider all the available switching states of the converter.

As indicated in Fig. 1, predictive power control [23], [45] and predictive voltage control [40]-[44] have been also implemented in MCs but due to space limitations, these techniques are not analyzed in this work. 


\section{Limitations, WeAKNESSES, OPEn QUESTIONS AND FUTURE TRENDS}

As well it has been demonstrated that predictive control is a very powerful alternative to control MCs, this technique also presents some limitations and weaknesses. Some of them are:

- Variable switching frequency.

- High dependence on the predictive model quality.

- High sampling frequency.

- Sensitive to variation on the parameters.

- High computational cost.

As highlighted in Part I of this paper, the MC presents different advantages in term of size and weight, allowing the operation with sinusoidal source and load currents, regeneration capability among others, but despite all the rewards, there exists two main disadvantages in the MC topology (as long as the maximum voltage transfer ratio is not needed by the load [46]): the output voltage is limited to $86 \%$ of the input, and secondly, any perturbation in the supply deteriorates the quality of the load side, due to the absence of storage elements. But, as mentioned in the first part of this paper, in order to solve this issue, in [47] has been proposed the implementation of a hybrid power converter which connects an auxiliary voltage source in the dc-link of the indirect matrix converter (IMC), obtaining unity voltage transfer capability even under severe distortions in the source voltage. Additionally, a PCC strategy is proposed in this work for the auxiliary voltage source, where the current reference is given by a PI linear controller and predictive control selects the duty cycle for the pulse-width modulator, ensuring balanced power in the converter and unity voltage ratio. Predictive control can select be used to select the optimum state of the converter to control directly the primary control variable or it can be used to calculate the duty cycle to be applied for a set of space vectors to control indirectly the primary control variable by a space vector modulation strategy.

The MC topology has also limited capability to perform power factor correction or active damping, since the reactive power is directly proportional to the modulation index, amplitude of the input line voltage and output line current, and inversely proportional to the currentto-voltage displacement angle at the converter. Special hybrid modulation schemes applied to the sparse matrix converter topology have been studied to manage reactive power for a purely reactive loads [48]. However, if the instantaneous output currents of the $\mathrm{MC}$ are equal to zero, then no reactive input power can be provided with any modulation scheme [46].

In MC topologies, the energy storage is located at the input filter (despite this is very small), therefore the MC topology suffer from an aging process, limiting the lifetime of the converter. There is a relation between the capacitor lifetime and the capacitance value, calculated in terms of the volume of the dielectric material and the current ripple at a given operating voltage. For an specific type of dielectric material, an operating temperature and rated voltage, the capacitance value, and therefore, the lifetime of the input filter capacitors is given by the maximum input current ripple.

The losses and capacitor value are significantly lower in a $\mathrm{MC}$ than for an equally sized dc-link capacitor in a two-level voltage dc-link back-to-back converter (V-BBC) [46]. However, a minimum internal energy storage needs to be provided in order to meet the dynamic requirements imposed by the load. For high-load dynamics, extended ridethrough capability, or unconstrained reactive power compensation, the MC has not yet proved to be the most appropriate solution.

The matrix converter should hence be selected for high frequency applications, where the conduction losses are dominant. However, the cause of electromagnetic interference (EMI) problems in power electronics is fast switching of high currents and voltages within the power converter systems. Other causes of EMI are supply voltage interruptions, dips, unbalance, surges and fluctuations that are also reflected in the load side because of the direct topology [19], [20].

In order to reduce the input current ripple, the input displacement power factor and other causes of EMI, many solutions have been reported. For example, it is possible to select a proper filter resonant frequency, which may limit the converter performance because the $L C$ resonant frequency is a function of the system impedance. This impedance varies with the operating conditions of the system. Also, it is possible to adopt a high switching frequency. The first solution results in lower THD of the output currents, however the converter losses and the EMI increase significantly and finally, the converter efficiency with both solutions decreases [21], [22]. Another suitable method consists of emulating a damping resistor placed in parallel with the filter capacitor in such way that the harmonic currents caused by the resonances flow through this resistor.

Active damping improves high quality of the input currents and the instantaneous reactive power minimization on the input side. However, this method only mitigates higher current harmonics resulted from the switching operation and cannot ensure a sinusoidal input current, particularly when the source voltage is distorted. To overcome these issues, in the implementations done with predictive control, the term that minimizes the reactive power at the input side is replaced by a direct control of the source currents. This approach forces the input currents to follow the sinusoidal value, regardless of the distortion level at the input side [25], [49].

In all the studied cases where predictive control has been applied, it has been demonstrated a very good performance, being a very simple method for implementation. But in each case, only a second order $L C$ filter has been used. An industrial type system with a MC should be considered with an EMI input filter (not only singlestage $L C$ filter), in order to provide results which are immediately useful to the industry area. Additionally, there are two major reasons for using an EMI input filters. 
The first reason is to prevent electromagnetic interference of the power electronic converter with the integrated electronic systems, and the second reason is to avoid the malfunction of the power converter operation caused by sources of electromagnetic noise in the surrounds. Also there are some requirements that the EMI filter has to fulfill:

- Minimum filter attenuation requirement at given frequencies.

- Minimization of input current fundamental displacement factor.

- Limitation of the volume/energy stored in the filter components.

- Sufficient passive damping for minimum losses, in order to avoid oscillations also for no-load operation.

- Avoiding of filter resonances at the multiples of switching frequency.

- Minimization of the filter output impedance, in order ensures system stability and minimizes control design constrains

As it has been showed, predictive control has been successfully implemented in MCs. But, there are still some open topics for research as well as some trends in the work with this type of power converters and control strategy.

Finally, an exhaustive comparison between predictive control and classical control techniques must be taking into consideration in order to demonstrate the simplicity and feasibility of the strategy.

\section{CONCLUSIONS}

The main contribution of this paper has been to presents an overview of different topologies, control strategies and applications for MCs where predictive control techniques are applied. The main limitations of simple predictive control applied to traditional MCs fall on its power factor correction or active damping capability and variable switching frequency producing resonance in the input filter. This resonance generates high distortion on the input current which are also reflected in the output current due to the direct connection between input and output sides of the converter. The performance of predictive control strategies depends on the digital platform and the predictive strategy since it is based on an iterative and finite-horizon optimization of the load model.

Named limitations and weaknesses of predictive control in matrix converters, constitute a future open topic for research and trends to be done by researchers. It has been shown that predictive control can be recognized as an attractive control approach, with significant benefits such as flexibility, versatility, and performance, with real applications of the power converters and electric drives.

\section{REFERENCES}

[1] J. Rodriguez, M. Rivera, J. W. Kolar, and P. W. Wheeler, "A review of control and modulation methods for matrix converters," Industrial Electronics, IEEE Transactions on, vol. 59, no. 1, pp. 58-70, 2012.
[2] C. F. Calvillo, A. Olloqui, F. Martell, J. L. Elizondo, A. Avila, M. E. Macias, M. Rivera, and J. Rodriguez, "Comparison of model based predictive control and fuzzy logic control of a dfig with an indirect matrix converter," in IECON 2012 - 38th Annual Conference on IEEE Industrial Electronics Society, 25-28 Oct. 2012 2012, pp. 6063-6068.

[3] P. Correa, J. Rodriguez, M. Rivera, J. R. Espinoza, and J. W. Kolar, "Predictive control of an indirect matrix converter," Industrial Electronics, IEEE Transactions on, vol. 56, no. 6, pp. 1847-1853, 2009.

[4] J. D. Dasika and M. Saeedifard, "An on-line fault detection and a post-fault strategy to improve the reliability of matrix converters," in Applied Power Electronics Conference and Exposition (APEC), 2013 Twenty-Eighth Annual IEEE, 17-21 March 2013 2013, pp. $1185-1191$.

[5] A. A. Heris, E. Babaei, and S. H. Hosseini, "A new shunt active power filter based on indirect matrix converter," in Electrical Engineering (ICEE), 2012 20th Iranian Conference on, 15-17 May 2012 2012, pp. 581-586.

[6] E. Lee, L. Kyo-Beum, L. Jae-Sik, L. Youngil, and S. Joong-Ho, "Predictive current control for a sparse matrix converter," in Power Electronics and Motion Control Conference (IPEMC), 2012 7th International, vol. 1, 2-5 June 2012 2012, pp. 36-40.

[7] F. Morel, J. M. Retif, L.-S. Xuefang, B. Allard, and P. Bevilacqua, "A predictive control for a matrix converter-fed permanent magnet synchronous machine," in Power Electronics Specialists Conference, 2008. PESC 2008. IEEE, 15-19 June 2008 2008, pp. $15-21$.

[8] M. Rivera, J. L. Elizondo, M. E. Macias, O. M. Probst, O. M. Micheloud, J. Rodriguez, C. Rojas, and A. Wilson, "Model predictive control of a doubly fed induction generator with an indirect matrix converter," in IECON 2010 - 36th Annual Conference on IEEE Industrial Electronics Society, 7-10 Nov. 2010 2010, pp. 2959-2965.

[9] M. Rivera, J. Rodriguez, J. R. Espinoza, and H. Abu-Rub, "Instantaneous reactive power minimization and current control for an indirect matrix converter under a distorted ac supply," Industrial Informatics, IEEE Transactions on, vol. 8, no. 3, pp. 482-490, 2012.

[10] M. Rivera, C. Rojas, J. Rodriguez, and J. Espinoza, "Methods of source current reference generation for predictive control in a direct matrix converter," Power Electronics, IET, vol. 6, no. 5, 2013.

[11] M. Rivera, R. Vargas, J. Espinoza, J. Rodriguez, P. Wheeler, and C. Silva, "Current control in matrix converters connected to polluted ac voltage supplies," in Power Electronics Specialists Conference, 2008. PESC 2008. IEEE, 15-19 June 2008 2008, pp. 412-417.

[12] M. Rivera, A. Wilson, C. A. Rojas, J. Rodriguez, J. R. Espinoza, P. W. Wheeler, and L. Empringham, "A comparative assessment of model predictive current control and space vector modulation in a direct matrix converter," Industrial Electronics, IEEE Transactions on, vol. 60 , no. 2 , pp. 578-588, 2013.

[13] J. Rodriguez, J. Kolar, J. Espinoza, M. Rivera, and C. Rojas, "Predictive current control with reactive power minimization in an indirect matrix converter," in Industrial Technology (ICIT), 2010 IEEE International Conference on, 14-17 March 2010 2010, pp 1839-1844.

[14] C. Rojas, M. Rivera, J. Rodriguez, A. Wilson, J. Espinoza, F. Villarroel, and P. Wheeler, "Predictive control of a direct matrix converter operating under an unbalanced ac source," in Industrial Electronics (ISIE), 2010 IEEE International Symposium on, 4-7 July 2010 2010, pp. 3159-3164.

[15] R. Vargas, J. Rodriguez, U. Ammann, and P. W. Wheeler, "Predictive current control of an induction machine fed by a matrix converter with reactive power control," Industrial Electronics, IEEE Transactions on, vol. 55, no. 12, pp. 4362-4371, 2008.

[16] R. Vargas, J. Rodriguez, C. Rojas, and P. Wheeler, "Predictive current control applied to a matrix converter: An assessment with the direct transfer function approach," in Industrial Technology (ICIT), 2010 IEEE International Conference on, 14-17 March 2010 2010, pp. 1832-1838.

[17] L. Yulong, C. Nam-Sup, C. Honnyong, and F. Z. Peng, "Carrierbased predictive current controlled pulse width modulation for matrix converters," in Power Electronics and Motion Control Conference, 2009. IPEMC '09. IEEE 6th International, 17-20 May 2009 2009, pp. 1009-1014. 
[18] P. Cortes, S. Kouro, B. La Rocca, R. Vargas, J. Rodriguez, J. Leon, S. Vazquez, and L. Franquelo, "Guidelines for weighting factors design in model predictive control of power converters and drives," 2009, pp. 1-7, Gippsland, Australia.

[19] M. Rivera, P. Correa, J. Rodriguez, I. Lizama, and J. Espinoza, "Predictive control of the indirect matrix converter with active damping," in Power Electronics and Motion Control Conference, 2009. IPEMC '09. IEEE 6th International, 17-20 May 2009 2009, pp. $1738-1744$.

[20] M. Rivera, P. Correa, J. Rodriguez, I. Lizama, J. Espinoza, and C. Rojas, "Predictive control with active damping in a direct matrix converter," in Energy Conversion Congress and Exposition, 2009. ECCE 2009. IEEE, 20-24 Sept. 2009 2009, pp. 3057-3062.

[21] M. Rivera, J. Rodriguez, W. Bin, J. R. Espinoza, and C. A. Rojas, "Current control for an indirect matrix converter with filter resonance mitigation," Industrial Electronics, IEEE Transactions on, vol. 59, no. 1, pp. 71-79, 2012.

[22] M. Rivera, C. Rojas, Rodri, x, J. guez, P. Wheeler, W. Bin, and J. R. Espinoza, "Predictive current control with input filter resonance mitigation for a direct matrix converter," Power Electronics, IEEE Transactions on, vol. 26, no. 10, pp. 2794-2803, 2011.

[23] S. K. M. Ahmed, A. Iqbal, H. Abu-Rub, and P. Cortes, "Model predictive control of a three-to-five phase matrix converter," in Predictive Control of Electrical Drives and Power Electronics (PRECEDE), 2011 Workshop on, 14-15 Oct. 2011 2011, pp. 3639.

[24] M. Rivera, J. Rodriguez, J. Espinoza, and W. Bin, "Reduction of common-mode voltage in an indirect matrix converter with imposed sinusoidal input/output waveforms," in IECON 2012 38th Annual Conference on IEEE Industrial Electronics Society, 25-28 Oct. 2012 2012, pp. 6105-6110.

[25] M. Rivera, J. Rodriguez, P. W. Wheeler, C. A. Rojas, A. Wilson, and J. R. Espinoza, "Control of a matrix converter with imposed sinusoidal source currents," Industrial Electronics, IEEE Transactions on, vol. 59, no. 4, pp. 1939-1949, 2012.

[26] J. Rodriguez, J. Espinoza, M. Rivera, F. Villarroel, and C. Rojas, "Predictive control of source and load currents in a direct matrix converter," in Industrial Technology (ICIT), 2010 IEEE International Conference on, 14-17 March 2010 2010, pp. 1826-1831.

[27] F. Villarroel, J. Espinoza, C. Rojas, C. Molina, and E. Espinosa, "A multiobjective ranking based finite states model predictive control scheme applied to a direct matrix converter," in IECON 2010 36th Annual Conference on IEEE Industrial Electronics Society, 7-10 Nov. 2010 2010, pp. 2941-2946.

[28] F. Villarroel, J. Espinoza, C. Rojas, C. Molina, and J. Rodriguez, "Application of fuzzy decision making to the switching state selection in the predictive control of a direct matrix converter," in IECON 2011 - 37th Annual Conference on IEEE Industrial Electronics Society, 7-10 Nov. 2011 2011, pp. 4272-4277.

[29] F. Villarroel, J. R. Espinoza, C. A. Rojas, J. Rodriguez, M. Rivera, and D. Sbarbaro, "Multiobjective switching state selector for finitestates model predictive control based on fuzzy decision making in a matrix converter," Industrial Electronics, IEEE Transactions on, vol. 60, no. 2, pp. 589-599, 2013.

[30] R. Vargas, U. Ammann, and J. Rodriguez, "Predictive approach to increase efficiency and reduce switching losses on matrix converters," Power Electronics, IEEE Transactions on, vol. 24, no. 4, pp. 894-902, 2009.

[31] M. Lopez, M. Rivera, C. Garcia, J. Rodriguez, R. Pena, J. Espinoza, and P. Wheeler, "Predictive torque control of a multi-drive system fed by a six-leg indirect matrix converter," in Industrial Technology (ICIT), 2013 IEEE International Conference on, 2528 Feb. 2013 2013, pp. 1642-1647.

[32] C. Ortega, A. Arias, and J. Espina, "Predictive vector selector for direct torque control of matrix converter fed induction motors," in Industrial Electronics, 2009. IECON '09. 35th Annual Conference of IEEE, 3-5 Nov. 2009 2009, pp. 1240-1245.

[33] C. Ortega, A. Arias, and et al., "Predictive direct torque control of matrix converter fed permanent magnet synchronous machines," in Industrial Electronics (ISIE), 2010 IEEE International Symposium on, 4-7 July 2010 2010, pp. 1451-1455.

[34] J. Rodriguez, J. Kolar, J. Espinoza, M. Rivera, and C. Rojas, "Predictive torque and flux control of an induction machine fed by an indirect matrix converter," in Industrial Technology (ICIT), 2010 IEEE International Conference on, 14-17 March 2010 2010, pp. 1857-1863.

[35] J. Rodriguez, J. Kolar, and et al., "Predictive torque and flux control of an induction machine fed by an indirect matrix converter with reactive power minimization," in Industrial Electronics (ISIE), 2010 IEEE International Symposium on, 4-7 July 2010 2010, pp. 3177-3183.

[36] S. M. M. Uddin, S. Mekhilef, M. Rivera, and J. Rodriguez, "A fcs-mpc of an induction motor fed by indirect matrix converter with unity power factor control," in Industrial Electronics and Applications (ICIEA), 2013 8th IEEE Conference on, 19-21 June 2013 2013, pp. 1769-1774.

[37] R. Vargas, U. Ammann, B. Hudoffsky, J. Rodriguez, and P. Wheeler, "Predictive torque control of an induction machine fed by a matrix converter with reactive input power control," Power Electronics, IEEE Transactions on, vol. 25, no. 6, pp. 1426-1438, 2010.

[38] R. Vargas, M. Rivera, J. Rodriguez, J. Espinoza, and P. Wheeler, "Predictive torque control with input pf correction applied to an induction machine fed by a matrix converter," in Power Electronics Specialists Conference, 2008. PESC 2008. IEEE, 15-19 June 2008 2008, pp. 9-14.

[39] L. Zakaria and K. Barra, "Predictive direct torque and flux control of an induction motor drive fed by a direct matrix converter with reactive power minimization," in Networking, Sensing and Control (ICNSC), 2013 10th IEEE International Conference on, 10-12 April 2013 2013, pp. 34-39.

[40] D. J. Cook, M. Catucci, P. W. Wheeler, J. C. Clare, J. S. Przybyla, and B. R. Richardson, "Development of a predictive controller for use on a direct converter for high-energy physics applications," Industrial Electronics, IEEE Transactions on, vol. 55, no. 12, pp. 4325-4334, 2008.

[41] E. F. Reyes, A. J. Watson, J. C. Clare, and P. W. Wheeler, "Comparison of predictive control strategies for direct resonant high voltage dc power supply," in Power Electronics, Machines and Drives (PEMD 2012), 6th IET International Conference on, 27-29 March 2012 2012, pp. 1-6.

[42] P. Gamboa, J. F. Silva, S. F. Pinto, and E. Margato, "Predictive optimal matrix converter control for a dynamic voltage restorer with flywheel energy storage," in Industrial Electronics, 2009. IECON '09. 35th Annual Conference of IEEE, 3-5 Nov. 2009 2009, pp. 759-764.

[43] S. Yusoff, L. De Lillo, P. Zanchetta, and P. Wheeler, "Predictive control of a direct ac/ac matrix converter power supply under nonlinear load conditions," in Power Electronics and Motion Control Conference (EPE/PEMC), 2012 15th International, 4-6 Sept. 2012 2012, pp. DS3c.4-1-DS3c.4-6.

[44] S. Yusoff, L. De Lillo, P. Zanchetta, P. Wheeler, P. Cortes, and J. Rodriguez, "Predictive control of a direct ac/ac matrix converter for power supply applications," in Power Electronics, Machines and Drives (PEMD 2012), 6th IET International Conference on, 27-29 March 2012 2012, pp. 1-6.

[45] M. Ortega, F. Jurado, and J. Carpio, "Control of indirect matrix converter with bidirectional output stage for micro-turbine," Power Electronics, IET, vol. 5, no. 6, pp. 659-668, 2012.

[46] T. Friedli, J. W. Kolar, J. Rodriguez, and P. W. Wheeler, "Comparative evaluation of three-phase ac-ac matrix converter and voltage dc-link back-to-back converter systems," Industrial Electronics, IEEE Transactions on, vol. 59, no. 12, pp. 4487-4510, 2012.

[47] T. Wijekoon, C. Klumpner, P. Zanchetta, and P. W. Wheeler, "Implementation of a hybrid ac-ac direct power converter with unity voltage transfer," Power Electronics, IEEE Transactions on, vol. 23, no. 4, pp. 1918-1926, 2008.

[48] F. Schafmeister and J. W. Kolar, "Novel modulation schemes for conventional and sparse matrix converters facilitating reactive power transfer independent of active power flow," in Power Electronics Specialists Conference, 2004. PESC 04. 2004 IEEE 35th Annual, vol. 4, 2004 2004, pp. 2917-2923 Vol.4.

[49] M. Rivera, J. Rodriguez, J. R. Espinoza, T. Friedli, J. W. Kolar, A. Wilson, and C. A. Rojas, "Imposed sinusoidal source and load currents for an indirect matrix converter," Industrial Electronics, IEEE Transactions on, vol. 59, no. 9, pp. 3427-3435, 2012. 